\title{
Intraocular Pressure Based on Dynamic Bidirectional Applanation and Air-puff Tonometry: A Comparative Study
}

\author{
Ayse E Bahadir Kilavuzoglư ${ }^{1}$, Cemile B Cosar ${ }^{2}$, Ali RC Celebi ${ }^{3}$, Ugur E Al Parmak ${ }^{4}$
}

\begin{abstract}
Aim: The aim of this study is to compare intraocular pressure (IOP) in healthy eyes measured via dynamic bidirectional applanation and air-puff tonometry, and to evaluate the effect of age, gender, the spherical equivalent (SE), mean keratometry (Kmean), corneal hysteresis (CH), and the corneal resistance factor (CRF) on IOP measurements.

Materials and methods: IOP measured in 956 healthy eyes using the ocular response analyzer (ORA) and air-puff tonometer was compared in this cross-sectional retrospective study. Correlations between IOP, and age, gender, $\mathrm{SE}, \mathrm{Kmean}, \mathrm{CH}$, and CRF were investigated using univariate and multivariate analyses. Bland-Altman plots were used to determine the level of agreement between the IOP values obtained with the two devices: IOP via air-puff tonometer (IOP-air-puff) and corneal-compensated IOP (IOPcc) using ORA (ORA-IOPcc). Linear mixed modeling was used to evaluate the effects of the study parameters on IOP. Intermethod reliability was established by calculating intraclass correlation coefficients ( $r$ ). Results: The mean age of the patients was $39.56 \pm 14.44$ years. The mean IOPair-puff and ORA-IOPcc were $16.72 \pm 2.37 \mathrm{~mm} \mathrm{Hg}$ and $13.75 \pm$ $3.12 \mathrm{~mm} \mathrm{Hg}$, respectively $(p<0.001)$. The mean $\mathrm{CH}$ and CRF were $11.14 \pm 1.61 \mathrm{~mm} \mathrm{Hg}$ and $10.53 \pm 1.65 \mathrm{~mm}$ Hg, respectively. Multivariate analysis showed that both $\mathrm{CH}$ and CRF were significantly correlated with IOP-air-puff and ORA-IOPcc $(p<0.001)$. The $95 \%$ limit of agreement for IOP-air-puff and IOPcc was -2.843 to 8.784 . There was a significant correlation between IOP-air-puff and ORA-IOPcC $(r=0.443, p<0.001)$; the $R^{2}$ value was 0.196 .

Conclusion: A low degree of agreement was noted between IOP-air-puff and ORA-IOPcc. The present findings show that air-puff tonometry overestimates IOP, as compared to ORA.

Clinical significance: IOP based on air-puff tonometry must be interpreted in conjunction with other ophthalmologic findings and the same IOP measuring device should be used for follow-up evaluations.

Keywords: Air-puff tonometry, Corneal hysteresis, Corneal resistance factor, Intraocular pressure, Ocular response analyzer.

Journal of Current Glaucoma Practice (2019): 10.5005/jp-journals-10078-1251
\end{abstract}

\section{INTRODUCTION}

IOP is well known to be the only modifiable risk factor for the development and progression of glaucoma. ${ }^{1-3}$ The IOP level and IOP fluctuation during follow-up are the most important risk factors for the progression of glaucoma. ${ }^{1,3-5}$ An increase in the mean IOP of as little as $1 \mathrm{~mm} \mathrm{Hg}$ is important; ${ }^{3}$ therefore, accurate assessment of IOP is crucial for the diagnosis of glaucoma and optimal treatment.

IOP was first measured via Goldmann applanation tonometry in the mid-1950s. In its current incarnation (little has changed since the 1950s), Goldmann applanation tonometry remains a popular and widely used method of tonometry, although it is not accurate enough to measure the true IOP. ${ }^{6}$ As such, the air-puff tonometer, ocular response analyzer (ORA) (Reichert, Corp., Buffalo, NY), dynamic contour tonometer, and other commercially available handheld tonometry devices have been developed.

Air-puff tonometry is a form of applanation tonometry that employs a calibrated column of compressed air to briefly flatten the corneal apex. It is the most common type of tonometry used for routine eye examination and screening purposes. Air-puff tonometry is used to measure IOP without anesthetizing the ocular surface and is associated with a lower risk of contamination than other types that use tonometers that make contact with the cornea during measurement. Similar to applanation devices, airpuff tonometers are affected by such corneal characteristics such as central corneal thickness (CCT) and ocular rigidity. ${ }^{7}$

The ORA is a modern tonometer designed to measure IOP while taking into consideration the variability in each patient's
${ }^{1-4}$ Department of Ophthalmology, Acibadem Mehmet Ali Aydinlar University, Istanbul, Turkey

Corresponding Author: Ayse E Bahadir Kilavuzoglu, Department of Ophthalmology, Acibadem Mehmet Ali Aydinlar University, Istanbul, Turkey, Phone: +90 5333473265, e-mail: ebrubahadir@gmail.com

How to cite this article: Bahadir Kilavuzoglu $A E$, Cosar $C B$, et al. Intraocular Pressure Based on Dynamic Bidirectional Applanation and Air-puff Tonometry: A Comparative Study. J Curr Glaucoma Pract 2019;13(2):68-73.

Source of support: Nil

Conflict of interest: None

corneal biomechanical properties, as well as to measure corneal biomechanical parameters. Unlike conventional noncontact tonometry, the ORA measures both inward and outward movements of the cornea. As such, the ORA provides 2 IOP values (Goldmann-correlated IOP [IOPg] and IOPcc]), and novel metrics indicative of corneal biomechanical properties ( $\mathrm{CH}$ and the CRF). IOPg is the mean of the 2 applanation pressures (inward and outward). IOPcc is an empirically derived value indicative of IOP that is independent of corneal thickness and biomechanical properties. ${ }^{8}$ $\mathrm{CH}$ is a measure of the viscous dampening properties of the cornea, whereas CRF is correlated to CCT and is strongly associated with corneal elastic response.

The aim of the present study is to compare IOP in healthy eyes measured via dynamic bidirectional applanation and air-puff

() The Author(s). 2019 Open Access This article is distributed under the terms of the Creative Commons Attribution 4.0 International License (https://creativecommons. org/licenses/by-nc/4.0/), which permits unrestricted use, distribution, and non-commercial reproduction in any medium, provided you give appropriate credit to the original author(s) and the source, provide a link to the Creative Commons license, and indicate if changes were made. The Creative Commons Public Domain Dedication waiver (http://creativecommons.org/publicdomain/zero/1.0/) applies to the data made available in this article, unless otherwise stated. 
tonometry, and to evaluate the effect of age, gender, the SE, Kmean, $\mathrm{CH}$, and $\mathrm{CRF}$ on IOP measurements.

\section{Materials and Methods}

This retrospective study included 956 eyes in 478 patients that presented to the ophthalmology clinic for a routine eye examination. Patients were consecutively included in the study according to the inclusion and exclusion criteria. Inclusion criteria were ORA and air-puff tonometry measurement at the time of examination and a waveform score (WS) $\geq 3.5 .^{9}$ The presence of any ocular disease, including glaucoma (cup-disc ratio $>0.3$, cupdisc asymmetry between eyes, and an IOP $>22 \mathrm{~mm} \mathrm{Hg}$ via both air-puff tonometry and ORA measurement), a history of ocular surgery or trauma, contact lens use, and regular use of eye drops were the exclusion criteria. All the patients underwent a full ophthalmological examination, including best-corrected visual acuity based on the Snellen acuity chart, slit-lamp biomicroscopy, and dilated fundus examination. Patients with a best-corrected visual acuity $<20 / 25$ and with corneal astigmatism of $\geq 3$ diopters ${ }^{6}$ were excluded from the study. The study protocol was approved by the Institutional Review Board and was performed in accordance with the tenets of the Declaration of Helsinki.

The primary outcome measures were age, gender, SE, Kmean, CH, CRF, and two IOP measurements-IOP via an air-puff tonometer (IOP-air-puff) and IOPcc via the ORA (ORA-IOPCC). The IOP-air-puff value was the mean of three air-puff tonometer measurements (CT-80 Non-contact Tonometer, Topcon, Japan). The CT-80 is reported to provide results comparable to those provided by a Goldmann applanation tonometer, in terms of the magnitude and repeatability of the measured IOP. ${ }^{10}$ Among the four consecutive ORA measurements performed in each patient, the measurement with the highest WS was accepted as the IOPcC value. All measurements were performed between 0800 and 1800 . Diurnal variation in IOP, which is a well-known phenomenon, ${ }^{11-13}$ was not taken into consideration because air-puff tonometer and ORA IOP measurements were performed consecutively during the same examination.

Statistical analysis was performed using the NCSS (Number Cruncher Statistical System) 2007 (Kaysville, Utah, USA). Descriptive statistical methods (frequency, percentage, and mean \pm SD), the Shapiro-Wilk test, and graphics were used to evaluate the study data. The Wilcoxon signed rank test was used to compare IOPair-puff and ORA-IOPcc values. Linear mixed modeling was used to evaluate the effects of the study parameters on IOP-air-puff, ORA-IOPCC, CH, and CRF. Pearson's correlation analysis was used to assess the strength of correlation between the measurements. Bland-Altman plots were used to evaluate the degree of agreement between IOP-air-puff and ORA-IOPcc. Intermethod reliability was established by calculating intraclass correlation coefficients $(r)$. Results were evaluated at the $95 \% \mathrm{Cl}$ and the level of statistical significance was set at $p<0.05$.

\section{Results}

In total, 266 (55.6\%) of the patients were females and 212 (44.4\%) were males. The mean age of the patients was $39.56 \pm 14.44$ years (range: 11-91 years). Kmean, and mean SE, IOP-air-puff, ORA-IOPcc, $\mathrm{CH}$, and CRF are shown in Table 1. Univariate analysis showed that $\mathrm{CH}$ and CRF were significantly correlated with IOP-air-puff (Table 2); for every $1 \mathrm{~mm} \mathrm{Hg}$ increase in $\mathrm{CH}$, IOP-air-puff increased $0.243 \mathrm{~mm} \mathrm{Hg}$,
Table 1: Summary of study parameters

\begin{tabular}{ll}
\hline Variables & Mean $\pm S D($ min-max $)$ \\
\hline SE & $-0.80 \pm 2.15(-12.75$ to 6.50$)$ \\
Kmean & $43.14 \pm 1.49(36.25-47.75)$ \\
IOP-air-puff & $16.72 \pm 2.37(10.00-21.00)$ \\
ORA-IOPcc & $13.75 \pm 3.12(5.30-24.90)$ \\
CH & $11.14 \pm 1.61(6.30-17.30)$ \\
CRF & $10.53 \pm 1.65(6.00-15.60)$ \\
\hline
\end{tabular}

ORA-IOPcc, corneal-compensated IOP measured via ocular response analyzer

and for every $1 \mathrm{~mm} \mathrm{Hg}$ increase in CRF, IOP-air-puff increased 0.816 $\mathrm{mm} \mathrm{Hg}$ ( $p<0.001$; linear mixed modeling). Multivariate analysis showed that age, $\mathrm{CH}$, and $\mathrm{CRF}$ were significantly correlated with IOP-air-puff (Table 2); for every 1 year increase in age, IOP-air-puff decreased $0.010 \mathrm{~mm} \mathrm{Hg}$, for every $1 \mathrm{~mm} \mathrm{Hg}$ increase in $\mathrm{CH}$, IOPair-puff decreased $1.174 \mathrm{~mm} \mathrm{Hg}$, and for every $1 \mathrm{~mm} \mathrm{Hg}$ increase in CRF, IOP-air-puff increased $1.845 \mathrm{~mm} \mathrm{Hg}(p=0.011, p<0.001$, and $p<0.001$ respectively; linear mixed modeling).

Univariate analysis showed that gender, age, Kmean, and $\mathrm{CH}$ were significantly correlated with IOPcc (Table 3); females had significantly lower ORA-IOPcc values than males ( $p=0.003)$; for every 1 year increase in age, ORA-IOPcc increased $0.043 \mathrm{~mm} \mathrm{Hg}$, for every 1-diopter increase in Kmean, ORA-IOPcc decreased $0.381 \mathrm{~mm} \mathrm{Hg}$, and for every $1 \mathrm{~mm} \mathrm{Hg}$ increase in $\mathrm{CH}$, ORA-IOPcc decreased $1.192 \mathrm{~mm} \mathrm{Hg}(p<0.001)$ (linear mixed modeling). According to multivariate analysis, $\mathrm{CH}$ and $\mathrm{CRF}$ were significantly correlated with ORA-IOPcc (Table 3); for every $1 \mathrm{~mm} \mathrm{Hg}$ increase in $\mathrm{CH}$, ORA-IOPcC decreased $3.512 \mathrm{~mm} \mathrm{Hg}$ and for every $1 \mathrm{~mm}$ $\mathrm{Hg}$ increase in CRF ORA-IOPcc increased $2.864 \mathrm{~mm} \mathrm{Hg}(p<0.001$; linear mixed modeling). Age was significantly correlated with $\mathrm{CH}_{\text {; }}$ for every 1 year increase in age, $\mathrm{CH}$ decreased $0.021 \mathrm{~mm} \mathrm{Hg}(p<$ 0.001 ; linear mixed modeling). Kmean was significantly correlated with $\mathrm{CH}$; for every 1-diopter increase in Kmean, $\mathrm{CH}$ increased 0.150 $\mathrm{mm} \mathrm{Hg}$ ( $p=0.001$; linear mixed modeling).

There was a significant difference between IOP-air-puff and ORA-IOPcc values ( $p<0.001$; Wilcoxon signed rank test); IOP-air-puff values were a mean $2.970 \mathrm{~mm} \mathrm{Hg}$ higher than ORA-IOPcc values (Fig. 1). Bland-Altman plots produced a $95 \%$ limit of agreement between IOP-air-puff and ORA-IOPcc of -2.84 to $8.78 \mathrm{~mm} \mathrm{Hg}$. The difference between IOP-air-puff and IOPcc increased as the mean of IOP-air-puff and ORA-IOPcc increased. A significant correlation was noted between IOP-air-puff and ORA-IOPcc $(r=0.443, p<0.001$; Pearson's correlation analysis). IOP-air-puff values explained $19.6 \%$ of the variance in ORA-IOPcC values $\left(R^{2}=0.196\right)$. The intraclass correlation coefficient was 0.427 which indicated fair reliability between the two IOP measurements ( $95 \% \mathrm{Cl}$ : -0.072 to 0.666 ). As seen in Figures 2 and 3, the difference between the 2 IOP measurements increased as IOP-air-puff increased and decreased as ORA-IOPcc increased $(r=0.335, p<0.001$, and $r=-0.696, p<0.001$, respectively).

\section{Discussion}

In the present study, there was a significant difference in mean IOP measurements obtained via an air-puff tonometer (16.72 $\mathrm{mm} \mathrm{Hg}$ ) and ORA (13.75 $\mathrm{mm} \mathrm{Hg})$, even though they were positively correlated with each other. Furthermore, Bland-Altman plots showed that there were fairly wide intervals of agreement 
Table 2: Effect of study parameters on IOP-air-puff measurements

\begin{tabular}{|c|c|c|c|c|c|c|c|}
\hline & & & & $I O P-C$ & & & \\
\hline & & & & & & & \\
\hline & & Estimate & Std. error & $t$ & $p$ & Lower & Upper \\
\hline Univariate & Intercept & 16.771 & 0.153 & 109.921 & $<0.001^{*}$ & 16.471 & 17.070 \\
\hline & Gender (F) & -0.099 & 0.205 & -0.484 & 0.629 & -0.501 & 0.303 \\
\hline & Intercept & 16.845 & 0.297 & 56.805 & $<0.001^{*}$ & 16.262 & 17.427 \\
\hline & Age & -0.003 & 0.007 & -0.463 & 0.643 & -0.017 & 0.011 \\
\hline & Intercept & 16.690 & 0.107 & 155.654 & $<0.001^{*}$ & 16.480 & 16.901 \\
\hline & SE & -0.032 & 0.043 & -0.742 & 0.458 & -0.115 & 0.052 \\
\hline & Intercept & 20.578 & 2.822 & 7.293 & $<0.001^{*}$ & 15.036 & 26.120 \\
\hline & Kmean & -0.090 & 0.065 & -1.370 & 0.171 & -0.218 & 0.039 \\
\hline & Intercept & 14.003 & 0.520 & 26.927 & $<0.001^{*}$ & 12.983 & 15.024 \\
\hline & $\mathrm{CH}$ & 0.243 & 0.046 & 5.308 & $<0.001^{*}$ & 0.153 & 0.333 \\
\hline & Intercept & 8.118 & 0.415 & 19.543 & $<0.001^{*}$ & 7.303 & 8.934 \\
\hline & CRF & 0.816 & 0.039 & 21.009 & $<0.001^{*}$ & 0.740 & 0.892 \\
\hline Multivariate & Intercept & 11.592 & 1.674 & 6.923 & $<0.001^{*}$ & 8.302 & 14.881 \\
\hline & Gender (F) & 0.099 & 0.110 & 0.894 & 0.372 & -0.118 & 0.315 \\
\hline & Age & -0.010 & 0.004 & -2.554 & $0.011^{\dagger}$ & -0.018 & -0.002 \\
\hline & SE & 0.006 & 0.026 & 0.245 & 0.807 & -0.045 & 0.058 \\
\hline & Kmean & -0.030 & 0.038 & -0.803 & 0.422 & -0.105 & 0.044 \\
\hline & $\mathrm{CH}$ & -1.174 & 0.059 & -19.903 & $<0.001^{*}$ & -1.290 & -1.059 \\
\hline & CRF & 1.845 & 0.057 & 32.524 & $<0.001^{*}$ & 1.734 & 1.957 \\
\hline
\end{tabular}

Linear mixed model, ${ }^{*} p<0.01,{ }^{\dagger} p<0.05$

Table 3: Effect of study parameters on ORA-IOPcc measurements

\begin{tabular}{|c|c|c|c|c|c|c|c|}
\hline & & \multicolumn{6}{|c|}{ ORA-IOPCC } \\
\hline & & \multirow[b]{2}{*}{ Estimate } & \multirow[b]{2}{*}{ Std. error } & \multirow[b]{2}{*}{$t$} & \multirow[b]{2}{*}{$p$} & \multicolumn{2}{|c|}{$95 \% \mathrm{Cl}$} \\
\hline & & & & & & Lower & Upper \\
\hline \multirow[t]{12}{*}{ Univariate } & Intercept & 14.176 & 0.195 & 72.521 & $<0.001^{*}$ & 13.792 & 14.561 \\
\hline & Gender (F) & -0.775 & 0.262 & -2.957 & $0.003^{*}$ & -1.290 & -0.260 \\
\hline & Intercept & 12.058 & 0.374 & 32.201 & $<0.001^{*}$ & 11.322 & 12.794 \\
\hline & Age & 0.043 & 0.009 & 4.796 & $<0.001^{*}$ & 0.025 & 0.060 \\
\hline & Intercept & 13.742 & 0.139 & 98.970 & $<0.001^{*}$ & 13.469 & 14.014 \\
\hline & SE & -0.004 & 0.056 & -0.079 & 0.937 & -0.115 & 0.106 \\
\hline & Intercept & 30.173 & 3.610 & 8.358 & $<0.001^{*}$ & 23.082 & 37.263 \\
\hline & Kmean & -0.381 & 0.084 & -4.554 & $<0.001^{*}$ & -0.545 & -0.217 \\
\hline & Intercept & 27.031 & 0.575 & 47.035 & $<0.001^{*}$ & 25.903 & 28.159 \\
\hline & $\mathrm{CH}$ & -1.192 & 0.051 & -23.574 & $<0.001^{*}$ & -1.292 & -1.093 \\
\hline & Intercept & 14.818 & 0.692 & 21.424 & $<0.001^{*}$ & 13.461 & 16.175 \\
\hline & CRF & -0.102 & 0.064 & -1.580 & 0.114 & -0.228 & 0.025 \\
\hline \multirow[t]{7}{*}{ Multivariate } & Intercept & 22.828 & 0.146 & 155.934 & $<0.001^{*}$ & 22.540 & 23.116 \\
\hline & Gender (F) & 0.003 & 0.010 & 0.292 & 0.771 & -0.016 & 0.021 \\
\hline & Age & $2.164 \times 10^{-4}$ & $3.508 \times 10^{-4}$ & 0.617 & 0.538 & $4.729 \times 10^{-4}$ & 0.001 \\
\hline & SE & $-1.107 \times 10^{-4}$ & 0.002 & -0.048 & 0.962 & -0.005 & 0.004 \\
\hline & Kmean & -0.002 & 0.003 & -0.717 & 0.474 & -0.009 & 0.004 \\
\hline & $\mathrm{CH}$ & -3.512 & 0.005 & -650.380 & $<0.001^{*}$ & -3.522 & -3.501 \\
\hline & CRF & 2.864 & 0.005 & 559.460 & $<0.001^{*}$ & 2.854 & 2.874 \\
\hline
\end{tabular}

Linear mixed model, ${ }^{*} p<0.01$

ORA-IOPcc; corneal-compensated IOP measured via ocular response analyzer

for intermethod analysis, and agreement varied depending on the IOP level. The wide limits of agreement between these methods indicate that one IOP value cannot be satisfactorily substituted for another.
The diagnosis and follow-up of glaucoma is primarily dependent on IOP measurement. Nonetheless, there is no clear line between a safe and an unsafe IOP, but for screening purposes, an IOP $>22 \mathrm{~mm} \mathrm{Hg}$ is considered an important risk factor for the 


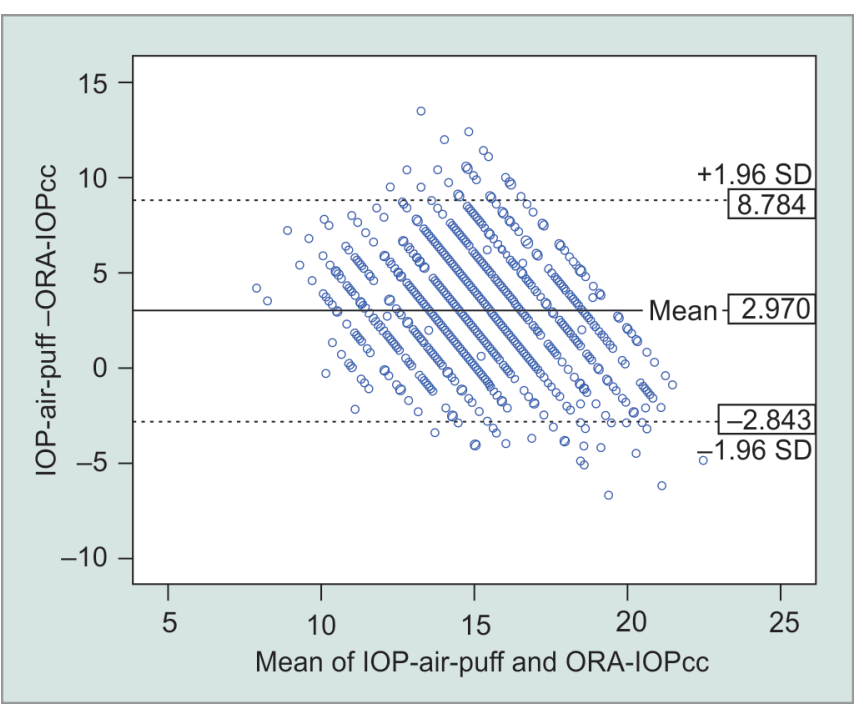

Fig. 1: Bland-Altman plots of the difference in IOP-air-puff and ORA (ORA-IOPcC), vs the mean of the 2 measurements

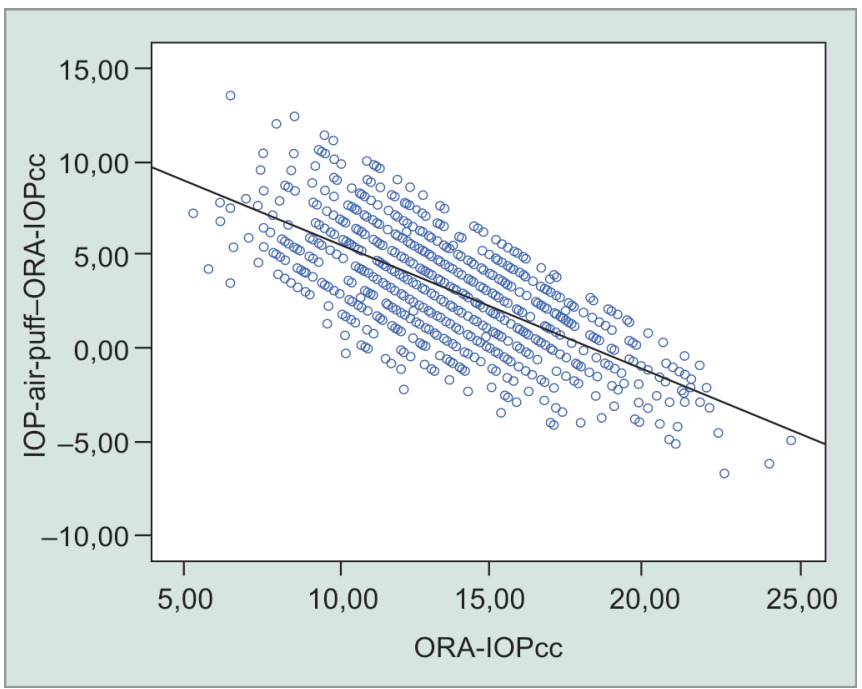

Fig. 3: Correlation between ORA-IOPcC, and the difference between IOP-air-puff and ORA-IOPcC $(r=-0.696, p<0.001)$

development of glaucomatous damage. Goldmann applanation tonometry was once considered the gold standard for IOP measurement, but the procedure is affected by corneal physical properties, of which CCT and corneal viscoelasticity most strongly affect IOP measurements. ${ }^{6,14-16}$

The need for accurate IOP measurement has led to the development of a number of noncontact tonometry methods. The nature of the relationship between the cornea and IOP, and the level of agreement between different types of tonometers are not fully known. The air-puff tonometer is the most commonly used tonometry device, especially in clinics with high patient volume. The advantages of air-puff tonometry are that it does not require the use of anesthetic drops and is not associated with the risk of corneal abrasion during applanation. Additionally, there is no risk of transmitting infectious agents via the tonometer tip, as there is when using a Goldmann applanation tonometer. Despite these advantages, the reliability of IOP measurements obtained via airpuff tonometery remains controversial.

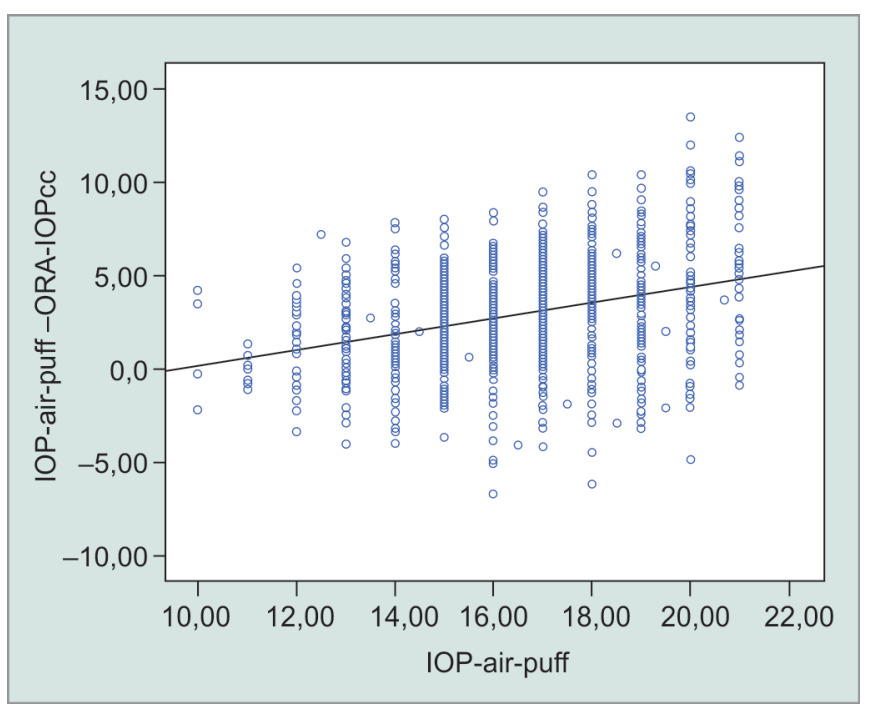

Fig. 2: Correlation between IOP-air-puff, and the difference between IOP-air-puff and ORA-IOPcC $(r=0.335, p<0.001)$

It is recommended that if an air-puff tonometry reading is high, then IOP should be measured using another type of tonometry device. ${ }^{17}$ According to Lagerlöf et al., ${ }^{18}$ air-puff tonometer IOP measurements of $20-30 \mathrm{~mm} \mathrm{Hg}$ are unreliable. In the present study, the difference between IOP-air-puff and ORA-IOPcc values increased as IOP-air-puff measurements increased $(r=0.335$, $p<0.001)$. A recently introduced noncontact tonometer, ORA, measures IOP taking into consideration corneal biomechanical properties and, thus, yields a more precise IOP measurement (IOPcc) in vivo. The intra- and interexaminer reproducibility of IOP via ORA is high, and together with corneal biomechanical metrics reliably measures IOP. ${ }^{19}$

Although it has been reported that modern versions of the air-puff tonometer correlate well with the Goldmann applanation tonometer, ${ }^{7}$ more recent studies report that it does not. IOP measured via air-puff tonometry was reported to be significantly higher than that measured via Goldmann applanation tonometry. ${ }^{17,20-22}$ Jorge et al. ${ }^{21}$ noted that air-puff tonometry (Reichert R7) overestimated IOP by about $1.7 \mathrm{~mm} \mathrm{Hg}$ on average, as compared to Goldmann applanation tonometry. The effect of corneal biomechanical properties on differences in IOP measured via air-puff tonometry and Goldmann applanation tonometry has been investigated. ${ }^{23} \mathrm{CRF}$, followed by CCT and $\mathrm{CH}$, were the best predictors of differences in IOP between the two techniques. Similarly, Jorge et al. ${ }^{21}$ reported that IOP based on air-puff tonometry was significantly correlated with CRF, but not other dimensional parameters of the eye (corneal curvature, anterior chamber depth, corneal diameter, axial length). They also investigated the level of agreement between air-puff tonometer IOP and IOPcc in 92 eyes, and reported that there was poor agreement between the measurements.

Kouchaki et al. ${ }^{24}$ investigated the agreement of four tonometry techniques (Goldmann applanation tonometer, dynamic contour tonometer, non-contact tonometer, and ocular response analyzer), and found that the agreement limit was relatively large even though the mean difference of measured IOP by dynamic contour tonometer, noncontact tonometer, and ocular response analyzer with Goldmann applanation tonometer was less than $2 \mathrm{~mm} \mathrm{Hg}$. They also stated that CCT and CRF were important influencing factors on 
the performance of tonometers. Similarly, Oncel et al. ${ }^{25}$ compared the IOP measurements of ocular response analyzer, dynamic contour, Goldmann applanation, and noncontact tonometry. They found that ORA IOPCC and dynamic contour tonometry readings were not clinically interchangeable with Goldmann applanation and noncontact tonometry readings.

The level of agreement between IOP measured via Goldmann applanation tonometer and ORA was also investigated and it is reported that ORA overestimates IOP, as compared to the Goldmann applanation tonometer. ${ }^{26-28}$ The mean difference between Goldmann applanation tonometer IOP and IOPcC was $8.3 \mathrm{~mm} \mathrm{Hg} .{ }^{26}$ On the other hand, Medeiros et al. ${ }^{29}$ investigated the level of agreement between IOP based on Goldmann applanation tonometer and IOPcc, and reported that the mean difference in IOP between the 2 devices was essentially zero, but Martinez-de-la-Casa et al.'s ${ }^{26}$ study population consisted of glaucoma patients, whereas Medeiros et al.' ${ }^{29}$ study included patients without glaucoma. Kotecha et al. ${ }^{30}$ investigated the agreement of IOP measurements obtained with the Goldmann applanation tonometer, the Pascal dynamic contour tonometer, and the Reichert ocular response analyzer and found that Goldmann applanation tonometry IOP measurements were approximately $2 \mathrm{~mm} \mathrm{Hg}$ lower than IOP measured with either the dynamic contour tonometer or the ORA. They stated that CRF was associated with the IOP measurement differences between these devices.

In the present study, multivariate analysis showed that gender, $\mathrm{SE}$, and Kmean were not correlated with IOP-air-puff or IOPcc values. IOP was reported to decrease with age. ${ }^{31}$ In the present study, age was significantly correlated with IOP-air-puff values, whereas age and ORA-IOPcC were not correlated. In addition, $\mathrm{CH}$ and CRF were significantly correlated with IOP-air-puff and ORA-IOPcC values, as expected.

It was reported that repeated tonometry causes a reduction in IOP. ${ }^{32-35}$ Recep et al. ${ }^{34}$ suggested a time interval of 2 minutes or 10 minutes between successive IOP measurements with a Goldmann applanation tonometer for accurate measurement. Gunvant et al. ${ }^{35}$ suggested a longer time interval ( $\geq 15$ minutes) between successive IOP measurements using a pulsatile ocular blood flow tonograph. In contrast, it was reported that repeating IOP measurements using an air-puff tonometer does not alter IOP. ${ }^{36}$ Due to the retrospective nature of the present study, the time interval between IOP-air-puff and ORA-IOPcc measurements, and the order in which they were performed are not known. Nonetheless, the ocular massage effect associated with Goldmann applanation tonometry did not occur during the present study's IOP-air-puff or ORA-IOPcc measurements.

Accurate direct measurement of IOP is only possible using a manometer and puncturing the eye, but currently, all IOP measuring devices used in outpatient clinics indirectly assess IOP. Air-puff tonometers are the easiest type of device to use, and air-puff tonometry is noninvasive and more comfortable for patients than conventional Goldmann applanation tonometry. As such, air-puff tonometry is a suitable method for screening of IOP despite the potential for erroneous IOP measurement. The ORA is a more reliable tonometer that it takes into account corneal physical properties, but it is not used as frequently as the air-puff tonometer. The present study aimed to determine the level of agreement between IOP measured via an air-puff tonometer and ORA. To the best of our knowledge, the present study is the largest population-based study on the level of agreement between IOPair-puff and ORA-IOPcC.

The study has some limitations. We do not have data about the Goldmann applanation tonometry measurements of the study population. As such, we could not compare the IOP-air-puff and ORA-IOPcc measurements with Goldmann applanation tonometry measurements, which is the study's major limitation. Another limitation of the present study is the lack of CCT measurements of the study population. As earlier studies reported, IOP measurements are strongly affected by corneal thickness. ${ }^{7,16}$ Also, although we considered that consecutive measurements first with air-puff tonometer or ORA might not have affected the readings of the second measurement, it could have had an impact on the results and that this is may be considered as a limitation of the study. In the present study, IOP was measured only in healthy eyes; greater variability may be encountered when measuring eyes with corneal pathology, a history of corneal surgery, and glaucoma. As such, the present findings should not be generalized to all patient populations.

\section{Conclusion}

There was a low degree of agreement between IOP-air-puff and ORA-IOPcc values. The air-puff tonometer overestimated IOP, as compared to IOP measured via ORA. The difference in IOP-air-puff and ORA-IOPcc values was significant, which is most probably due to the primary difference between these the two devices-during IOP measurement ORA takes into account individual corneal characteristics (corneal thickness and viscoelasticity), whereas the air-puff tonometer does not.

\section{Clinical Significance}

Although air-puff tonometer is the most common type of tonometry used for routine eye examination and screening purposes, it may erroneously give higher IOP values than other indirect IOP measurement techniques. It is better to take this into consideration while evaluating IOP air-puff values. Furthermore, the low degree of agreement between IOP-air-puff and ORA-IOPcC values revealed that the same IOP measuring device should be used for follow-up evaluations of the same patient.

\section{ACKNOWLedgment}

Scott B Evans, MSW, Ankara, Turkey (Language editor)

\section{References}

1. The AGIS Investigators. The Advanced Glaucoma Intervention Study (AGIS) 7: the relationship between control of intraocular pressure and visual field deterioration. Am J Ophthalmol 2000;130:429-440. DOI: 10.1016/S0002-9394(00)00538-9.

2. Kass MA, Heuer DK, et al. The Ocular Hypertension Treatment Study: a randomized trial determines that topical ocular hypotensive medication delays or prevents the onset of primary open-angle glaucoma. Arch Ophthalmol 2002;120:701-713. DOI: 10.1001/ archopht.120.6.701.

3. Leske MC, Heijl A, et al. Factors for glaucoma progression and the effect of treatment: the early manifest glaucoma trial. Arch Ophthalmol 2003;121:48-56. DOI: 10.1001/archopht.121.1.48.

4. Musch DC, Gillespie BW, et al. Intraocular pressure control and long-term visual field loss in the Collaborative Initial Glaucoma 
Treatment Study. Ophthalomogy 2011;118:1766-1773. DOI: 10.1016/ j.ophtha.2011.01.047.

5. Rao HL, Addepalli UK, et al. Relationship between intraocular pressure and rate of visual field progression in treated glaucoma. J Glaucoma 2013;22:719-724. DOI: 10.1097/IJG.0b013e318259b0c2.

6. Whitacre MM, Stein R. Sources of error with use of Goldmann-type tonometers. Surv Ophthalmol 1993;38:1-30. DOI: 10.1016/00396257(93)90053-A

7. De Moraes CGV, Prata TS, et al. Modalities of tonometry and their accuracy with respect to corneal thickness and irregularities. J Optom 2008;1:43-49. DOI: 10.3921/joptom.2008.43.

8. Roberts CJ. Concepts and misconceptions in corneal biomechanics. J Cataract Refract Surg 2014;40:862-869. DOI: 10.1016/j.jcrs.2014.04.019.

9. Lam AK, Chen D, et al. The usefulness of waveform score from the ocular response analyzer. Optom Vis Sci 2010;87:195-199. DOI: 10.1097/OPX.0b013e3181d1d940.

10. Ogbuehi KC. Assessment of the accuracy and reliability of the Topcon CT80 non-contact tonometer. Clin Exp Optom 2006;89:310-314. DOI: 10.1111/j.1444-0938.2006.00068.x.

11. David R, Zangwill L, et al. Diurnal intraocular pressure variations: an analysis of 690 diurnal curves. Br J Ophthalmol 1992;76:280-283. DOI: 10.1136/bjo.76.5.280.

12. Laiquzzaman M, Bhojwani R, et al. Diurnal variation of ocular hysteresis in normal subjects: relevance in clinical context. Clin Experiment Ophthalmol 2006;34:114-118. DOI: 10.1111/j.14429071.2006.01185.x.

13. Shen $M$, Wang J, et al. Diurnal variation of ocular hysteresis, corneal thickness, and intraocular pressure. Optom Vis Sci 2008;85:1185-1192. DOI: 10.1097/OPX.0b013e31818e8abe.

14. Dielemans I, Vingerling JR, et al. Reliability of intraocular pressure measurement with the Goldmann applanation tonometer in epidemiological studies. Graefes Arch Clin Exp Ophthalmol 1994:232:141-144. DOI: 10.1007/BF00176782.

15. Ehlers N, Bramsen $\mathrm{T}$, et al. Applanation tonometry and central corneal thickness. Acta Ophthalmol (Copenh) 1975;53:34-43. DOI: 10.1111/j.1755-3768.1975.tb01135.x.

16. Sakalar YB, Keklikci U, et al. Comparison of different methods for measurement of intraocular pressure and evaluation of effect of central corneal thickness on measurement results. Turk J Ophthalmol 2010;40:156-159. DOI: 10.4274/tod.40.156.

17. Farhood QK. Comparative evaluation of intraocular pressure with an air-puff tonometer vs a Goldmann applanation tonometer. Clin Ophthalmol 2013;7:23-27. DOI: 10.2147/OPTH.S38418.

18. Lagerlöf $\mathrm{O}$. Airpuff tonometry vs applanation tonometry. Acta Ophthalmol (Copenh) 1990;68:221-224. DOI: 10.1111/j.17553768.1990.tb01909.x.

19. Moreno-Montanes J, Maldonado MJ, et al. Reproducibility and clinical relevance of the ocular response analyzer in nonoperated eyes: corneal biomechanical and tonometric implications. Invest Ophthalmol Vis Sci 2008;49:968-974. DOI: 10.1167/iovs.07-0280.

20. Schiano Lomeriello $D$, Lombardo $M$, et al. Repeatability of intra-ocular pressure and central corneal thickness measurements provided by a non-contact method of tonometry and pachymetry. Graefes Arch Clin Exp Ophthalmol 2011;249:429-434. DOI: 10.1007/s00417-010-1550-3.
21. Jorge J, Gonzalez-Meijome JM, et al. A comparison of the NCT Reichert R7 with Goldmann applanation tonometry and the Reichert ocular response analyzer. Ophthalmic Physiol Opt 2011;31:174-179. DOI: 10.1111/j.1475-1313.2010.00817.x.

22. Eraslan M, Cerman E, et al. Comparison of intraocular pressure measurements in healthy pediatric patients using three types of tonometers. Turk J Ophthalmol 2017;47:1-4. DOI: 10.4274/tjo.92593.

23. Tranchina $L$, Lombardo $M$, et al. Influence of corneal biomechanical properties on intraocular pressure differences between an air-puff tonometer and the Goldmann applanation tonometer. J Glaucoma 2013;22:416-421. DOI: 10.1097/IJG.0b013e31824cafc9.

24. Kouchaki $\mathrm{B}$, Hashemi $\mathrm{H}$, et al. Comparison of current tonometry techniques in measurement of intraocular pressure. J Curr Ophthalmol 2016;29:92-97. DOI: 10.1016/j.joco.2016.08.010.

25. Oncel B, Dinc U, et al. Comparison of IOP measurement by ocular response analyzer, dynamic contour, Goldmann applanation, and contact tonometry. Eur J Ophthalmol 2009;19:936-941. DOI: 10.1177/112067210901900607.

26. Martinez-de-la-Casa JM, Garcia-Feijoo J, et al. Ocular response analyzer vs Goldmann applanation tonometry for intraocular pressure measurements. Invest Ophthalmol Vis Sci 2006;47: 4410-4414. DOI: 10.1167/iovs.06-0158.

27. Feizi S, Hashemloo A, et al. Comparison of the ocular response analyzer and the Goldmann applanation tonometer for measuring intraocular pressure after deep anterior lamellar keratoplasty. Invest Ophthalmol Vis Sci 2011;52:5887-5891. DOI: 10.1167/iovs.10-6771.

28. Renier C, Zeyen T, et al. Comparison of ocular response analyzer, dynamic contour tonometer and Goldmann applanation tonometer. Int Ophthalmol 2010;30:651-659. DOI: 10.1007/s10792-010-9377-9.

29. Medeiros FA, Weinreb RN. Evaluation of the influence of corneal biomechanical properties on intraocular pressure measurements using the ocular response analyzer. J Glaucoma 2006;15:364-370. DOI: 10.1097/01.ijg.0000212268.42606.97.

30. Kotecha A, White E, et al. Intraocular pressure measurement precision with the Goldmann applanation, dynamic contour, and ocular response analyzer tonometers. Ophthalmology 2010;117:730-737. DOI: 10.1016/j.ophtha.2009.09.020

31. FukuokaS, Aihara M, etal. Intraocular pressure in an ophthalmologically normal Japanese population. Acta Ophthalmol 2008;86:434-439. DOI: 10.1111/j.1600-0420.2007.01068.x.

32. Moses RA, Liu CH. Repeated applanation tonometry. Am J Ophthalmol 1968;66:89-91. DOI: 10.1016/0002-9394(68)91794-7.

33. Gaton DD, Ehrenberg M, et al. Effect of repeated applanation tonometry on the accuracy of intraocular pressure measurements. Curr Eye Res 2010;35:475-479. DOI: 10.3109/02713681003678824.

34. Recep OF, Hasiripi $H$, et al. Accurate time interval in repeated tonometry. Acta Ophthalmol Scand 1998;76:603-605. DOI: 10.1034/j.1600-0420.1998.760518.x.

35. Gunvant $P$, Watkins RJ, et al. Repeatability and effects of sequential measurements with POBF tonograph. Optom Vis Sci 2004;81: 794-799. DOI: 10.1097/00006324-200410000-00012.

36. Sorensen PN. The noncontact tonometer. Clinical evaluation on normal and diseased eyes. Acta Ophthalmol (Copenh) 1975;53: 513-521. DOI: 10.1111/j.1755-3768.1975.tb01771.x. 